\title{
La enseñanza del derecho en la economía del aprendizaje
}

\author{
Legal teaching into the learning economy
}

Josefa Dolores Ruiz Resa*

Recepción y evaluación de propuesta: 18/07/2017

Aceptación: 10/10/2017

Recepción y aceptación final: 31/05/2018

\begin{abstract}
Resumen: La hipótesis de este trabajo es que la etapa actual del capitalismo, que puede denominarse de la economía del aprendizaje, nos empuja a un modelo de comunidad política desigualitario y tiránico, aparentemente individualista pero en cuyo fondo subyace el poder de grandes empresas que nos abocan a un nuevo organicismo economicista y laboral, con nuevas formas de servidumbre humanas. Esta comunidad se articula de manera global a través de las TIC, y potencia la formación de profesionales competentes y empleables, también en derecho, desde una concepción de la educación y del propio derecho como industrias innovadoras. Se tratará de argumentar por qué se sostiene esto, exponiendo (1) en qué consiste el actual contexto socioeconómico y político en el que nos hallamos; (2) cómo este influye en un replanteamiento de las tipologías de profesiones jurídicas y de su ejercicio; y (3) qué implicaciones tiene para la enseñanza del Derecho. Palabras clave: economía del aprendizaje, enseñanza del derecho, competencias, organicismo.
\end{abstract}

* Profesora Titular de Filosofía del Derecho de la Universidad de Granada, España. Email: jruizr@ugr.es Investigadora en derechos humanos, participación y educación política, pensamiento jurídico-político y epistemología jurídica. Entre sus publicaciones recientes se encuentran los libros Los derechos de los trabajadores en el franquismo (2014-2015), Derecho y valores en las democracias constitucionales (2015), Teoría del Derecho (2016), Innovación docente y nuevas tecnologías (2017). 


\begin{abstract}
The hypothesis of this work is that the present stage of capitalism where we are, which can be called the economy of learning, pushes us towards a model of an unequal, tyranic, seemingly individualistic, political community. Nevertheless, the power of big companies underlies at its bottom, and drives us to a new economic and working Organicism, with new ways of human servitude. This community is globally structured thanks to ICT, and potentiates the training of competent and employable professionals, also in law, from a conception of education and law itself as innovating industries. I will try to explain why this is sustained, exposing (1) what the present socio-economic and political context in which we are consists of; (2) how this influences the rethinking of the types of legal professionals and their exercise; and (3) what implications it has for the teaching of law.
\end{abstract}

Key words: learning economy, legal teaching, skills, Organicism.

\title{
I. Introducción
}

En su libro Tomorrow Lawyer's ${ }^{1}$, Richard Susskind analiza lo que él entiende que son los retos a los que se ven sometidas las profesiones jurídicas: la reducción de costes, para ofrecer más por menos, la liberalización de los servicios legales (legal services), de manera que quienes no son juristas compitan también en el mercado del derecho (legal marketplace), y los cambios que las nuevas tecnologías de la información y la comunicación (TIC) están pergeñando sobre el trabajo legal (legal work). Según Susskind, esto implica cambios radicales para el mercado legal (legal market), los despachos jurídicos (law firms), los asesores jurídicos, los tribunales y jueces, y los consumidores de servicios legales (consumers of legal services). Teniendo esto en cuenta, la formación en derecho debería incorporar la formación en nuevas disciplinas como gestión de riesgos jurídicos (legal risk management), gestión de proyectos jurídicos (legal project management), ingeniería del conocimiento jurídico (legal knowledge engineering) y análisis de procesos jurídicos (legal process analysis).

1 Suskind, R., Tomorrow's Lawyers: An Introduction to Your Future, Oxford, Oxford University Press, 2013. 
La enseñanza del derecho en la economía del aprendizaje

Si nos fijamos bien, el lenguaje de Susskind nos aboca a una percepción de las profesiones jurídicas y de la formación en Derecho en términos claramente economicistas y empresariales, que las vinculan básicamente con las actividades e intereses propios de la esfera privada y las alejan de las ideas de servicio público; también se sustenta sobre una concepción de la tecnología, vinculada a las ciencias cognitivas, en especial a la inteligencia artificial (IA) y las telecomunicaciones, que parece alejarlas aún más de lo que ya lo hizo el positivismo legalista y su demanda de juristas tecnócratas, de sus conexiones con la tradición humanista de los saberes prácticos. Entre ellos se situaba la técnica pero también el arte y los saberes sobre las acciones humanas, estos últimos guiados por la prudencia, y en cuyo seno, como parte de la moral, se ubicó el saber jurídico bajo la denominación Iuris-prudentia. Sin embargo, con esta nueva percepción del conocimiento, el saber jurídico queda conectado con un nuevo paradigma que puede denominarse tecno-económico ${ }^{2}$.

En todo caso, Susskind no está inventando nada sino siguiendo el proceso de mercantilización y computerización del conocimiento, en este caso, el jurídico, proceso que ha sido institucionalizado por importantes e influyentes organizaciones internacionales como la Organización para la Cooperación y el Desarrollo Económicos (OCDE), el Banco Mundial (BM), la Unión Europea (UE) y otras organizaciones regionales de Estados, y a lo que no es ajena la propia Organización de las Naciones Unidas para la Educación, la Ciencia y la Cultura (UNESCO). De esta forma, se ha abierto paso en las agendas políticas internacionales y estatales lo que parece una nueva fase del capitalismo globalizado, la de la llamada economía del aprendizaje, la cual está trayendo también un cambio de régimen político, caracterizado por el

2 Vilaseca, J., Torrent, J., y Díaz, Á., La economía del conocimiento. Paradigma tecnológico y cambio estructural, Working Paper Series, UOC (Universitat Oberta de Catalunya), 2002. [Disponible en http://www.uoc.edu/in3/dt/20007/20007.pdf. Última visita $22 / 05 / 2018]$. Los autores sostienen que estamos ante un paradigma tecnológico, pero en mi opinión, estamos ante un paradigma de conocimiento que también incorpora lo económico como una dimensión fundamental. 
retroceso de la legalidad estatal y de las instituciones públicas que se ocupaban del control de su aplicación.

Percepciones como estas conducen a una idea de las profesiones jurídicas y de la formación para su ejercicio al margen de la organización política estatal en que se desarrollan, y de sus principios y valores jurídicos de organización y funcionamiento, a pesar de que las directrices de las organizaciones internacionales se dirijan a sus estados miembros; como si la creación, interpretación y aplicación del Derecho estuvieran al margen de lo público y fueran fundamentalmente el resultado de la acción en la esfera privada, identificada con el mercado o lugar de intercambio de bienes y servicios, de individuos particulares $\mathrm{u}$ organizados en colectivos como las empresas -sobre todo, grandes empresas-. De esta forma, pareciera que todas las relaciones humanas pueden reconducirse al intercambio de bienes y servicios que se producen en ese ámbito y que suelen regularse mediante contratos, y a la existencia de sus mecanismos habituales de resolución de conflictos, como el arbitraje o la mediación, los cuales discurren al margen de las jurisdicciones estatales y pueden llevarse a cabo por otro tipo de profesiones no jurídicas. En realidad, el desarrollo de estos mecanismos ha traído ya una liberalización de la gestión jurídica de los conflictos entre particulares, individual o colectivamente considerados.

Así pues, esta nueva fase de las relaciones humanas, caracterizada por una extensa significación economicista y tecnológica, redunda en la demanda de un modelo de profesiones jurídicas, no necesariamente ejercido por personas con titulaciones oficiales en Derecho, universitarias o no, pensadas para ser desempeñadas por/en cierto tipo de empresas, principalmente, las llamadas industrias intensivas del conocimiento: tecnología, finanzas, telecomunicaciones, educación, salud y servicios a empresas intensivos de conocimiento; sin perder de vista que estas empresas son la ficción jurídica que agrupa a individuos con un elevado poder adquisitivo y, por consiguiente, con un gran poder de negociación e influencia, no sólo en la esfera del mercado sino también en el de las instituciones públicas, nacionales e internacionales. Dado que estos individuos y sus empresas constituyen un pequeño porcentaje de la población mundial, eso significa que el resto de los seres humanos 
no son contemplados como clientes de las profesiones jurídicas del futuro, que se ejercerían para una élite. Tal circunstancia nos puede abocar a un escenario de desigualdad y desprotección de los intereses y las demandas de estas personas, similar al que se daba en las etapas anteriores a la positivización y al reconocimiento igual de las garantías procesales, en el marco de las constituciones de los Estados de Derecho y las declaraciones de organizaciones internacionales del siglo XX. Es probable que esta desigualdad y desprotección se intensifiquen ante la desaparición paulatina de servicios públicos como la asistencia letrada gratuita $u$ otros tipos de asesoría jurídica que, con mayor o menor eficacia, garantiza el Estado como parte del contenido de los derechos de su ciudadanía. Como en épocas pasadas, los conflictos que se originen entre las personas de clases bajas y menor poder adquisitivo (cada vez más numerosas, según se deduce del aumento de la pobreza a nivel mundial y de la precarización de las condiciones de trabajo que ha traído la última crisis económica), se volverán a gestionar desde dispositivos jurídicos de control y disciplina, bajo conceptos jurídicos indeterminados como el orden público o la seguridad nacional.

En la medida en que quienes ejercen las profesiones jurídicas se ocupan de la interpretación y aplicación del derecho creado por unas determinadas instancias de poder -Estados u otro tipo de organismos sociales, individuos particulares-, se buscará su capacitación para interpretarlo y aplicarlo a fin de conseguir los objetivos dispuestos por esas instancias. No extraña entonces que cada cambio de régimen político se acompañe también de un cambio en la formación jurídica, creando nuevas estructuras formativas, nuevos planes de estudios y manuales, y con nuevo personal si el anterior no se adapta. Y, realmente, es en un cambio de régimen político en lo que estamos ahora; es decir, 1) en el paso de los gobiernos estatales en torno al interés general hacia la gobernanza de una sociedad/economía global, donde se justifica el retroceso de los Estados en el ámbito de la protección de los derechos de su ciudadanía, para redirigir sus políticas públicas (fiscales, laborales, educativas, sociales) hacia la protección y fomento de los intereses de ciertos grupos de individuos que ni siquiera forman parte de su ciudadanía, los cuales propugnan la mercantilización del conocimiento 
innovador, convertido en la fuente más importante de riqueza y desarrollo; 2) en la reconfiguración de las comunidades sociales en que se integran los humanos, las cuales se virtualizan, retifican y empresarizan, transmutando el tiempo de ocio en tiempo de formación de por vida para la innovación incesante, ya que el conocimiento humano se convierte en pieza fundamental del capital de las empresas; cambiando así la misma condición humana, hasta hacer de la servidumbre laboral un propósito de vida más o menos consciente.

Por lo tanto, la reflexión sobre la enseñanza del derecho nos aboca a pensar también en el tipo de comunidades en que vivimos. A este respecto, la hipótesis de este trabajo es que la etapa actual del capitalismo, que puede denominarse de la economía del aprendizaje, nos empuja a un modelo de comunidad política desigualitario y tiránico, aparentemente individualista pero en cuyo fondo subyace el poder de grandes empresas, que nos abocan a un nuevo organicismo económico y laboral, con nuevas formas de servidumbre humanas. Esta comunidad, que tiene como fuente jurídica principal el contrato entre individuos y grupos con desigual poder de negociación, se articula de manera global a través de las TIC, y potencia la formación de profesionales competentes y empleables, también en derecho, desde una concepción de la educación y del propio derecho como industrias innovadoras.

En las siguientes páginas, se tratará de argumentar por qué se sostiene esto, exponiendo (1) en qué consiste el actual contexto socioeconómico y político en el que nos hallamos; (2) cómo este influye en un replanteamiento de las tipologías de profesiones jurídicas y de su ejercicio; y (3) qué implicaciones tiene para la enseñanza del Derecho. En cualquier caso, los cambios que induce el nuevo modelo de sociedad/ economía se están aplicando al ámbito de las profesiones jurídicas y de la enseñanza del Derecho, sin tener demasiado en cuenta sus especificidades, las inercias del mundo académico jurídico y de sus gremios profesionales, o las dinámicas internas de poder de sus comunidades políticas. La ausencia de este análisis previo y la aplicación, sin más, de modelos de innovación y gestión del conocimiento que provienen de otras industrias podrían desembocar en resultados imprevistos. 
La enseñanza del derecho en la economía del aprendizaje

\section{La economía del aprendizaje}

Utilizamos esta expresión para hacer referencia a una fase del modo de producción capitalista en la que las relaciones socio-económicas (infraestructura) y jurídico-políticas (superestructura) giran en torno a una concepción del conocimiento que es el resultado de la transformación de la información o conocimiento explícito en nuevo conocimiento, todo lo cual es objeto de mercantilización. Pero la economía del aprendizaje constituye, a su vez, una evolución de la sociedad/ economía del conocimiento, desde la perspectiva institucional (II.1) y epistemológica (II.2.), desde las cuales se delimitan sus características (II.3). Veamos cómo.

\section{II.1. Institucionalización}

Empecemos analizando los documentos de las organizaciones que, a lo largo de las últimas décadas del siglo XX, han contribuido a situar el conocimiento y el aprendizaje en el núcleo de las políticas económicas, haciendo de la política educativa una parte de aquellas.

Así, la información constituye para la UNESCO un instrumento de conocimiento, pero no es conocimiento. Conocer tampoco es "simple comprobación de los hechos" sino que supone dominar algunas competencias cognitivas, críticas y teóricas, cuyo fomento es precisamente el objeto de las sociedades del conocimiento. "La avalancha de información puede aplastarnos pero el conocimiento es precisamente lo que permite 'orientarse en el pensamiento"'3. La información es un flujo de mensajes mientras que el conocimiento se crea a través de ese flujo y su anclaje en las convicciones y los compromisos del sujeto que conoce 4 . El conocimiento transforma el "dato bruto" de la información en conocimiento, tras lo cual se produce una informalización del

3 UNESCO, Informe mundial: hacia las sociedades del conocimiento, París, 2005, pág. 51.

4 Nonaka, I, Byosière, $\mathrm{Ph}$., "La creación de conocimiento regional: un proceso de desarrollo social", en CLUSTER CONOCIMIENTO, Las sociedades del conocimiento, Bilbao, 2000, pág. 8. Cfr. Vilaseca, J., Torrent, J., y Díaz, Á., La economía del conocimiento. Paradigma tecnológico y cambio estructural, op. cit, pág. 7. 
conocimiento o acondicionamiento del conocimiento en información para su transmisión, manipulación y consumo, interconexión a la que la UNESCO califica como "círculo virtuoso" .

Para la UNESCO, "las sociedades del conocimiento" (en plural, ya que no cree que pueda hablarse de un modelo exportable a todos los lugares del planeta sin tener en cuenta sus especificidades y sus conocimientos locales) deberían garantizar un aprovechamiento compartido del saber, para mejorar las condiciones democráticas y el respeto a derechos como la libertad de expresión y opinión, el derecho a la educación, y el derecho a participar en la vida cultural y el progreso científico ${ }^{6}$. Se potenciaría así una inteligencia colectiva, sobre todo gracias al uso de las TIC, que, en principio, abre las puertas a una mejora de la participación ciudadana en el gobierno de su comunidad. La sociedad del conocimiento llevará así a la conclusión de que todo conocimiento, incluido el de los expertos, pueda ser cuestionado y revisado ${ }^{7}$.

La UNESCO utiliza también la expresión "sociedad del aprendizaje", siguiendo los trabajos de Hutchins y Husén, para referirse a una sociedad en la que la formación no está limitada a ciertas edades de la vida humana ni a las instituciones educativas ${ }^{8}$. La UNESCO admite que el "mundo cambiante" al que se enfrentan los seres humanos exige tener diversas profesiones, lo que obliga a su vez a un "aprendizaje de por vida". Tal aprendizaje garantiza el desarrollo personal y cultural de los individuos pero también el desarrollo económico. En todo caso, la conexión entre los progresos de la educación y los progresos de la economía ya los había señalado la UNESCO en un informe de 1973, titulado Aprender a ser. La educación del futuro, donde uno de sus autores, Edgar Fauré, sostenía que no era posible determinar las causalida-

5 UNESCO, Informe mundial: hacia las..., op. cit. pág. 51.

Ibidem, pp. 18 y 207 y ss.

7 Krüguer, K., "El concepto de 'sociedad del conocimiento'”, Revista bibliográfica de geografia y ciencias sociales, Universidad de Barcelona, XI, $\mathrm{n}^{\circ}$ 683, 25 de octubre de 2006. Disponible en http://www.ub.edu/geocrit/b3w-683.htm (última visita 30/06/2017).

8 UNESCO, Informe mundial: hacia las..., op. cit., pág. 61 y ss. 
La enseñanza del derecho en la economía del aprendizaje

des respectivas entre ambos tipos de progreso ${ }^{9}$. A través del informe La educación encierra un tesoro, ${ }^{10}$ elaborado para la UNESCO por la Comisión Internacional de Educación sobre la educación para el siglo XXI, y presidida por Jaques Delors, se indicaba que la educación a lo largo de la vida se basa en cuatro pilares ${ }^{11}$ : aprender a conocer (y aprender a aprender, para lo que se considera esencial la capacidad de buscar, jerarquizar y organizar la información que nos proporcionan las $\mathrm{TIC}^{12}$ ), aprender a hacer (adquiriendo no sólo una calificación profesional sino una competencia que capacite al individuo para hacer frente a gran número de situaciones y a trabajar en equipo), aprender a vivir juntos (respetando los valores de pluralismo, comprensión mutua y paz), y aprender a ser (obrar con creciente capacidad de autonomía, de juicio y de responsabilidad personal). Estos cuatro pilares inspirarán, a nivel mundial, buena parte de los elencos de competencias en los que se sostiene que deben formarse los individuos para garantizar sus empleos y, con ellos, el progreso socia $1^{13}$.

9 Faure, E., Herrera, F., Kaddoura, A.-R., López, H., Petrovski, A., V. Rahnema, M., Champion Ward, F., Aprender a ser. La educación del futuro, Alianza-UNESCO, 1973, pág. 28 y ss. Versión española Carmen Paredes de Castro. Disponible en http:// unesdoc.unesco.org/images/0013/001329/132984s.pdf. (última visita 30/06/2017).

${ }^{10}$ UNESCO, La educación encierra un tesoro, Madrid, Santillana/UNESCO, 1997.

11 Ibidem, pág. 36

12 UNESCO, Informe mundial: hacia las..., op. cit., p. 80.

${ }^{13}$ Así, por ejemplo, la OCDE, The definition and selection of key competencies executive summary, 27/5/2005, pág. 4 (Disponible en http://www.oecd.org/edu/skills-beyondschool/definitionandselectionof competenciesdeseco.htm, última visita 30/06/2017) propone 3 categorías de competencias que definen una personalidad humana: las competencias relativas al uso de herramientas de manera interactiva (usar el lenguaje, símbolos y textos, de manera interactiva, usar el conocimiento y la información de manera interactiva, y usar las tecnologías interactivamente); las competencias relativas a la interacción en grupos homogéneos (relacionarse bien con los otros, cooperar, gestionar y resolver conflictos); y las competencias que tienen que ver con actuar autónomamente (actuar en un panorama amplio, formar y dirigir planes de vida y proyectos personales y hacer valer derechos, intereses, límites y necesidades). La UE recoge en la Recomendación del Parlamento Europeo y del Consejo de 18 de diciembre de 2006 sobre las competencias clave para el aprendizaje permanente (2006/962/CE), las siguientes ocho competencias clave: comunicación en la lengua materna, comunicación en lenguas extranjeras, competencia matemática y competencias básicas en ciencia y tecnología, competencia digital, aprender a aprender, competencias cívicas 
Por su parte, la OCDE empezó a utilizar la expresión "economía del conocimiento o basada en el conocimiento" (knowledge economy o knowledge-based economy), a partir de la observación del comportamiento de determinadas economías, las cuales se busca convertir en modelos para todo el planeta, justificándose así su papel de economías dominantes o líderes en la economía global. De manera concreta, la OCDE alude con estas expresiones a aquellos países industrializados en los que el conocimiento se considera factor esencial de su crecimiento económico y de su competitividad frente a otras economías ${ }^{14}$. Pero este proceso es caracterizado a partir del funcionamiento de las denominadas industrias intensivas del conocimiento, esto es, las que producen tecnología, las finanzas, las telecomunicaciones, la educación, la salud y los llamados servicios a empresas intensivos de conocimiento. Teniendo en cuenta tales industrias, la OCDE consideró que la economía del conocimiento se basa directamente en la producción, distribución y el uso de conocimiento e información, y apunta como sus elementos definidores la inversión (pública o privada) en investigación, innovación, ciencia, tecnología y recursos humanos, ya que las economías se acercan cada vez más a sus fronteras tecnológicas, y no basta con imitar sino que es necesario innovar ${ }^{15}$.

La OCDE también ha utilizado la expresión "gestión del conocimiento" y "sociedad del aprendizaje", en su informe Knowledge Management in the Learning Society 16 , para dar título a una serie de estudios

y sociales, sentido de la iniciativa y espíritu de empresa y conciencia y expresión culturales.

14 OCDE, The Knowledge-based Economy, 1996; Boosting Innovation: The Cluster Approach, Paris, 1999; Science, Technology and Industry Scoreboard, 2001; Towards a knowledge-based economy, Paris, 2001.

15 Riesco González, M., El negocio es el conocimiento, Madrid, ediciones Díaz de Santos, 2006, pág. 4; González Romero, A., "Conocimiento, innovación y crecimiento económico", Mi+d. Revista electrónica (edición especial: 20 años de la ley de la ciencia. 19862006). Disponible en http://www.madrimasd.org/revista/revistaespeciall/articulos/ gonzalez.asp (última visita 01/06/2017). Camacho, J. A. y Rodríguez, M., "España ante la economía del conocimiento: el papel de los servicios a empresas intensivos de conocimiento", Revista Asturiana de Economía, Nº 31, 2004, pág.177 y 178.

${ }^{16}$ OCDE, París, 2000 (se ha consultado la edición española, La administración del conocimiento en la sociedad del aprendizaje, Bogotá/París, Mayol ediciones/ OCDE, 2006). 
La enseñanza del derecho en la economía del aprendizaje

acerca de "los procesos de conocimiento en funcionamiento en diferentes sectores" (entre ellos, pero no únicamente, el educativo, que sí se investiga, se dice, con especial atención, "para que el sistema educativo tradicional no quede marginado en la nueva sociedad basada en el conocimiento"). En este informe "se identifican numerosas formas en que es importante el entendimiento a nivel micro o sectorial de la economía basada en el conocimiento (...) Dichas percepciones son valiosas para los gobiernos, los sectores económicos y las empresas e instituciones públicas y privadas cuando buscan mejorar su conocimiento y el rendimiento de su aprendizaje, lo que es de creciente importancia para su funcionamiento en una sociedad de aprendizaje". Así pues, el ámbito de la educación no agota el aprendizaje, según lo entiende la OCDE ${ }^{17}$.

Por su parte, el BM (Banco Mundial) considera que los pilares de la "economía basada en el conocimiento" (knowledge-based economy) son: un régimen económico e institucional que aporte los incentivos para un uso eficiente del conocimiento existente y nuevo, donde florezca el emprendimiento; una población educada y capacitada que pueda crear, compartir y usar el conocimiento; un sistema eficiente de innovación compuesto por empresas, centros de investigación, universidades, think tanks, consultores y otras organizaciones que puedan generar un creciente stock de conocimiento global, asimilarlo y adaptarlo a las necesidades locales y crear nueva tecnología; y una infraestructura de tecnologías de la información y la comunicación que facilite la efectiva comunicación, diseminación y procesamiento de la información ${ }^{18}$.

${ }^{17} \mathrm{OCDE}$, La administración del conocimiento en la sociedad del aprendizaje, op. cit., pág. 9.

18 Banco Mundial Institute Development Studies, Building knowledge economies: Advanced strategies for development, Washington, The International Bank for Reconstruction and Development / The World Bank, 2007, pp. 23-24. Disponible en http://siteresources. worldbank.org/KFDLP/Resources/461197-1199907090464/BuildingKEbook.pdf. (Última visita 22/05/2018) 


\section{II.2. E1 paradigma tecno-económico}

Tras el desarrollo de la sociedad/economía del conocimiento/aprendizaje se detecta un paradigma tecno-económico que procede de una modulación reduccionista del llamado paradigma sistémico, de la complejidad, holístico o ecológico ${ }^{19}$, el cual emerge frente al paradigma positivista. De sus corrientes y disciplinas se van a tomar muchos de los tópicos que caracterizan la economía/sociedad del conocimiento/ aprendizaje y las innovaciones en sus industrias de referencia, entre ellas la educación, las TIC o la salud, para garantizar la formación en el tipo de profesiones y empleos que precisa. Se trata, por ejemplo, de la distinción entre conocimiento productivo y reproductivo, y de las nociones de conocimiento tácito, competencia, inteligencia modular, o aprendizaje como adaptación y respuesta a los problemas del medio mediante la creación de nuevo conocimiento. Pero, sobre todo, del paradigma sistémico se toma la percepción organicista de las relaciones entre los seres humanos y su entorno, la cual servirá, superpuesta paradójicamente al individualismo típico de la economía capitalista, para justificar la reducción del poder de los estados frente al de las organizaciones económicas y poner sus políticas públicas al servicio de los objetivos e intereses de aquellas. Veamos cómo.

Aunque, como es sabido, el paradigma sistémico se sustenta en la aportación transdisciplinar de múltiples saberes, su configuración se inicia a principios del siglo $\mathrm{XX}^{20}$, con las aportaciones de la biología -una biología que Capra denomina "organicista"21-, la cual concibe a los seres vivos como totalidades integradas, y abre el paso a una nueva ciencia que será fundamental en la consolidación de este paradigma: la ciencia de la ecología. También se detecta en los inicios del paradigma de la complejidad las aportaciones de la psicología de la Gestalt, que considera que el pensamiento que resuelve problemas no

\footnotetext{
19 Son las denominaciones dadas a este paradigma emergente, según Capra, F., La trama de la vida. Una nueva perspectiva de los sistemas vivos, Barcelona, Anagrama, 1998, pág. 37.

${ }^{20}$ Capra, F., La trama de la vida. Una nueva perspectiva de los sistemas vivos, op. cit.

${ }^{21}$ Ibidem, pág. 46.
} 
La enseñanza del derecho en la economía del aprendizaje

es reproductivo sino productivo y se basa en facultades como la comprensión y la intuición, idea muy influyente en la sociedad/economía del conocimiento/aprendizaje. En todo caso, también influyen en la configuración del paradigma sistémico las llamadas ciencias cognitivas, entre las que se incluyeron inicialmente 6 disciplinas: la filosofía, la psicología, la IA, la lingüística, la antropología y las neurociencias ${ }^{22}$. Muchos de sus conceptos, teorías e investigaciones se tomarán para justificar y delimitar los caracteres de la sociedad/economía del conocimiento/aprendizaje ${ }^{23}$.

A este respecto, las aportaciones de las ciencias cognitivas se van desarrollando a lo largo de las diversas fases por las que aquellas pasan $^{24}$ : en una fase inicial, más neopositivista y funcionalista, estas ciencias contribuyen a una visión computerizada de la mente humana, sobre la analogía entre cerebro y ordenador que concibe la cognición básicamente como procesamiento de información ${ }^{25}$. Pero ante la incapacidad para explicar cómo del procesamiento de la información se produce conocimiento nuevo, pasan a una segunda fase, donde se desarrolla la llamada "teoría de la mente" (por la cual poseemos una serie de conocimientos e inferencias que nos permiten interpretar y predecir lo que hacen otros), los estudios sobre la interacción mente-medio, y una concepción modular de la mente. En esta fase se retomarán los

${ }^{22}$ García García, E., "Teoría de la mente y ciencias cognitivas”, en Feito Grande (ed.), Nuevas perspectivas científicas y filosóficas sobre el ser humano, Madrid, Universidad Pontificia de Comillas, 2007, pág. 17 y ss.

${ }^{23} \mathrm{Su}$ influencia se aprecia en las investigaciones del Centro para la Investigación e Innovación Educativa (CERI) de la OCDE, que inició un proyecto en 1999 sobre "Ciencia del Aprendizaje e Investigación sobre el Cerebro", dando lugar a un informe en 2002 titulado La comprensión del cerebro: hacia una ciencia del aprendizaje, al que sigue el libro La comprensión del cerebro. El nacimiento de una ciencia del aprendizaje, París, OCDE, 2007 (trad. español publicada por la Universidad católica Silvia Henríquez, 2009).

${ }^{24}$ García García, "Teoría de la mente y ciencias cognitivas", op. cit., pág. 24 y ss.

${ }^{25}$ Estanny, A., "El impacto de las ciencias cognitivas en la filosofía de la ciencia", Eidós. Revista de Filosofia de la Universidad del Norte, 6, mayo, 2007, pp. 28-32 y 38-44. Disponible en http://www.redalyc.org/pdf/854/85400603.pdf (Última visita 22/05/2018). 
trabajos de la Gestalt, Vigotsky, Bartlett, Piaget o Guilford sobre el aprendizaje, la instrucción, la memoria y la creatividad ${ }^{26}$.

Pero, sin duda, es la aplicación del paradigma sistémico al ámbito de los estudios de la economía y la empresa lo que permite desarrollar los tópicos más significativos que conducen a esta nueva etapa de la economía global. Así, en el ámbito de la ciencia económica, el paradigma de la complejidad ha dado lugar a teorías como la de W. B. Arthur, para quien la economía es un proceso constante en el que los individuos interaccionan, adaptando continuamente sus estrategias y comportamientos para resolver los problemas del medio, haciendo que las estructuras (como por ejemplo, los mercados, las instituciones sociales y jurídicas o los patrones de precios) cambien continuamente. De esta manera contribuyen a que sus agentes cambien también sus comportamientos, con los que se reconstruyen, a su vez, las propias estructuras. Esta percepción es deudora de la concepción del aprendizaje como adquisición y modificación de conocimientos, habilidades, estrategias, creencias, actitudes y conductas ${ }^{27}$, la cual es debida a las aportaciones de las corrientes cognitivistas y las constructivistas de la psicología del aprendizaje $\mathrm{e}^{28}$.

En este contexto, ocupan un lugar fundamental la innovación y el cambio tecnológico, que Arthur concibe como una evolución de la propia tecnología, siendo esta considerada el resultado de procesos de aprendizaje ${ }^{29}$. En todo caso, la noción de innovación tecnológica debe

${ }^{26}$ Sobre estas cuestiones, véase Pozo, J. J. Teorías cognitivas del aprendizaje, Madrid, Morata, 1997, pág. 17 y ss.; Romo Santos, M., "Treinta y cinco años de pensamiento divergente. Teoría de la creatividad de Guilford”. Estudios de Psicología, número 27-28, 1987, pág. 175-192; Perales Palacios, F.J., "Desarrollo cognitivo y modelo constructivista en la enseñanza-aprendizaje de las ciencias", Revista Interuniversitaria de Formación del Profesorado, 13, Enero-Abril, 1992, pp. 173-189. Disponible en https://dialnet. unirioja.es/servlet/articulo?codigo=618847 (Última visita 22/05/2018).

${ }^{27}$ Schunk, D. H., Teorias del aprendizaje, trad. J.F. Javier Dávila Martínez, México, Pearson, 1997, pág. 2.

${ }^{28}$ Pozo, J. J., Teorías cognitivas del aprendizaje, ob. cit., pág. 17 y ss.

${ }^{29}$ Del mismo autor, véase: Arthur, W. B., Increasing returns and path dependence in the economy, Michigan, The Michigan University Press, Michigan, 1994; The Economy as an Evolving Complex System II, editado con Steven Durlauf y David Lane, Reading 
La enseñanza del derecho en la economía del aprendizaje

mucho a los trabajos de Arrow, David, Mokyr, Nelson o Rosenberg (partiendo, a su vez, de la afirmación de Schumpeter según la cual el avance del conocimiento tecnológico era la clave en el análisis económico $)^{30}$. En este punto, todas las innovaciones humanas, sean sociales o físicas se catalogan como tecnologías, sociales y físicas ${ }^{31}$. El derecho sería, pues, una tecnología social, cuya transformación responde a innovaciones introducidas por quienes cultivan los saberes jurídicos, desde las demandas sociales -de individuos o colectivos, como una empresa-, aunque también pueden venir inspiradas o desarrolladas por las ciencias robustas y las tecnologías que producen tecnologías físicas.

También el paradigma de la complejidad ha contribuido al desarrollo de las ciencias de la administración o gestión (management) y la psicología de las organizaciones y del trabajo, aplicadas fundamentalmente a las empresas, donde se han desarrollado categorías como las competencias, el capital intelectual y la gestión del conocimiento, las cuales alcanzan una gran importancia, ya que se consideran el motor de la ventaja competitiva de las organizaciones.

En la delimitación de estos conceptos será muy importante la distinción propuesta e la segunda mitad del siglo XX por el científico y filósofo Michael Polanyi ${ }^{32}$, entre conocimiento tácito y conocimiento explícito. Su presupuesto de partida es el rechazo de la idea, típica del positivismo científico, de que la ciencia es un conocimiento aislado, lo que quedaría refutado por la existencia de dos polos de conocimiento: el polo externo, equivalente a los elementos que se atribuyen al pensamiento racional desde la Ilustración, esto es, la objetividad, los estándares universales, y la articulación o formalización a través del

(Mass.), Addison-Wesley, 1997, 1997; The Nature of Technology: What it is and How it Evolves), Nueva York, The Free Press (Simon \& Schuster), 2009.

${ }^{30}$ Benavides, O. A., "La innovación tecnológica desde una perspectiva evolutiva", Cuadernos de Economía, XXIII, No 41, Bogotá, 2004, pág. 51.

${ }^{31}$ La distinción entre tecnologías físicas y sociales la desarrolla Nelson, R., Physical and Social Technologies, and Their Evolution, Pisa, Italia, LEM Working Paper, Series No. 9, June, Laboratory of Economics and Management, Sant'Anna School of Advance d Studies, 2003.

${ }^{32}$ Nye, M. J., Michael Polanyi and his generation: Origins of the Social Construction of Science, Chicago, University Chicago Press, 2011, pp. 15 y 7, 295 y 302. 
lenguaje; y el polo interno o personal, en el que se enraíza el anterior, y que equivale a las creencias prácticas heredadas, tradiciones, valores y prejuicios, y las informaciones e imágenes conceptuales y sensoriales, cuyas características primordiales son que se adquiere por la práctica y no puede ser articulado de manera explícita. Por esta razón, el polo interno constituye la dimensión tácita del conocimiento ${ }^{33}$.

La dualidad conocimiento tácito-conocimiento explícito parece superar y sustituir la dualidad teoría-práctica, y su presencia puede detectarse en la concepción de la espiral de conocimiento (tácito-explícito) que se da en las empresas, propuesta Nonaka y Takeuchi ${ }^{34}$, estudiosos de las organizaciones; o en la clasificación de los tipos de conocimiento propuesta por Lundvall ${ }^{35}$, otro influyente economista estudioso de las organizaciones al frente de la Dirección de Ciencia, Tecnología e Innovación -CERI- de la OCDE, y que participó también activamente en la preparación y el seguimiento de la Estrategia de Lisboa de 2000, cuyo objetivo declarado era convertir la economía de la UE en "la economía del conocimiento más competitiva y dinámica del mundo". Su clasificación, que hizo suya la $\mathrm{OCDE}^{36}$, distingue entre, por un lado, saber qué o know what y saber por qué o know why (conocimiento explícito o información), y, por otro, saber cómo o know how y saber quién o know who (conocimiento tácito, o verdadero conocimiento innovador). Para Lundvall ${ }^{37}$, el conocimiento es un activo, que puede funcionar como un input y un output en el proceso de producción. El input lo constituyen las competencias, el output la inno-

33 Polanyi, M., Personal Knowledge. Towards a Post-Critical Philosophy, Chicago, University Chicago Press, Chicago, 1962.

${ }^{34}$ Nonaka, I. y Takeuchi, H., The knowledge-creating company: How Japanese Companies Create the Dynamics of Innovation, New York-Oxford, Oxford University Press, 1995.

${ }^{35}$ Lundvall, B.-A. y Johnson, B., "The learning economy", Journal of Industry Studies, v1, No. 2, Diciembre, 1994, pp. 23-42; Lundvall, B.-A., "The economics of knowledge and learning", en Christensen, J. y Lundvall, B.-A. (eds.) Product Innovation, Interactive Learning and Economic Performance (Research on Technological Innovation, Management and Policy, vol. 8, Emerald Group Publishing Limited, 2004, pág. 21-42

36 OCDE, The Knowledge Based Economy, París, 1996. Disponible en https://www.oecd. org/sti/sci-tech/1913021.pdf (última visita 01/04/2016).

${ }^{37}$ Lundvall, B.-A., "The economics of knowledge and learning", op. cit. 
La enseñanza del derecho en la economía del aprendizaje

vación, pero todas ellas son susceptibles de convertirse en mercancías que pueden comprarse y poseerse de manera privada.

En relación a las competencias, se hallan con carácter general, conectadas a otros términos como aptitud (ability, aptitude) y destreza (skill), y según la abundante literatura que las ha estudiado, parece que el primero (aptitud) se refiere a las capacidades que permiten a alguien saber desempeñar las actividades de su puesto de trabajo, serían de tipo cognitivo; mientras, las habilidades harían referencia a desempeños de tipo físico o motor ${ }^{38}$. Desde estos planteamientos, se habla incluso de competencias en relación a las propias empresas y organizaciones, como si fueran organismos vivos: serían las "competencias corporativas", "metatécnica" o "competencias estratégicas" 39 . Igualmente se sostiene que no sólo aprenden los individuos sino también las empresas $^{40}$, las cuales se ven abocadas a hacerlo para poder subsistir e incrementar su valor.

Para Le Boterf (experto en ingeniería de recursos humanos, según su página web), las competencias no se reducen ni a saber ni a saber-hacer, ni pueden asimilarse por adquisición-formación. Así, se puede conocer el Derecho comercial pero redactar mal un contrato ${ }^{41}$. No obstante se sostiene también, atendiendo a la distinción entre aptitudes y habilidades dentro de las competencias, que las aptitudes no se aprenden, por ser innatas, permanentes, estables y sólo poder inferirse por la conducta; mientras que las destrezas, que sí son modificables, son observables y pueden ser aprendidas ${ }^{42}$. Pero, en ambos casos, el

38 Agut Nieto, S. y Gau Gumbau, R. M., "Una aproximación psicosocial al estudio de las competencias", Proyecto social: Revista de relaciones laborales, 9, 2001, pág. 13-24. (Disponible en https://dialnet.unirioja.es/servlet/articulo?codigo=209924. Última visita 22/05/2018)

39 Riesco González, M., "El enfoque por competencias en el EEES y sus implicaciones para la enseñanza y el aprendizaje", Tendencias Pedagógicas, 13, 2008, pp. 82 y 83.

40 Senge, P. M., The Fifth Discipline. The art and practice of the learning organization, Nueva York, Doubleday, 1990.

${ }^{41}$ Le Boterf, G., De la compétence. Essai sur un attracteur étrange, Paris, Les Éditions d'organisation, 1994, pág. 16.

42 Agut Nieto, S. y Gau Gumabau, R. M., "Una aproximación psicosocial al estudio de las competencias", op. cit. 
pasaje a la competencia se revela en la actualización de lo que sabemos en un contexto singular. La competencia sólo existe en cuanto que competencia en acto-acción: es la actuación del llamado conocimiento tácito o pegajoso ${ }^{43}$.

\section{II.3. Características de la economía del aprendizaje}

La declinación tecno-económica del enfoque sistémico y la institucionalización de un modelo de producción basado, según se ha señalado, en el funcionamiento de ciertas industrias muy influyentes en el ámbito internacional, ha desembocado en un tipo de economía/sociedad del conocimiento/aprendizaje, a la que de manera más simplificada aludiremos como economía del aprendizaje, debido a la centralidad de esos dos polos. Esta economía se caracteriza por lo siguiente: 1) en ella, el conocimiento no es igual a la información, pues ésta es un flujo de mensajes y el conocimiento surge cuando ese flujo se ancla en las convicciones y los compromisos del sujeto que conoce ${ }^{44}$; 2 ) una vez que se transforma el dato bruto en el que consiste la información en conocimiento, este se convierte en nueva información que se transmite, manipula y consume, generando nuevo conocimiento; 3) el proceso que transforma la información en conocimiento se denomina aprendizaje $^{45}$, mediante el cual ante los desafíos o problemas del entorno se moviliza y transfiere lo ya conocido para resolver esa perturbación del medio, generando así innovación ${ }^{46}$; 4) esta innovación se concibe, a su

${ }^{43}$ Lundvall, B.-A., "The economics of knowledge and learning", op. cit.; Von Hippel, E., "Sticky Information" and the Locus of Problem Solving: Implications for Innovation", Management Science, 40, Número 4, 1994, pp. 429-439.

${ }^{44}$ Vilaseca, Torrent y Díaz, op. cit.

${ }^{45}$ Martínez León, I. y Ruiz Mercader, J., "Los procesos de creación del conocimiento: el aprendizaje y la espiral de conversión del conocimiento", en XVI Congreso Nacional y XII Congreso hispano-francés de AEDEM: la empresa intangible, Asociación Europea de Dirección y Economía de la Empresa (AEDEM), Alicante, Universidad de Alicante, 2002, pág. 2.

${ }^{46}$ Lundvall, B.-Å., "Entender la función de la educación en la economía del aprendizaje: la contribución de la economía", en OCDE, La administración del conocimiento en la sociedad del aprendizaje, Bogotá, OCDE, Mayol ediciones, S.A., 2006, pág. 20. 
vez, como innovación fundamentalmente tecnológica, en la medida en que se reconducen a la categoría de tecnología todos los productos, materiales e inmateriales, del conocimiento humano; de ahí que se hable de tecnologías físicas (las tecnologías de la comunicación y la información, o la reproducción asistida), como de tecnologías sociales (las prácticas empresariales, los modelos de organización estatal, o los mismos sistemas de Investigación, Desarrollo e Innovación o I+D+i); finalmente, 5) el conocimiento así concebido se convierte en fuente de riqueza y, por lo tanto, de desarrollo y progreso, lo que justifica su captación, codificación, evaluación de su calidad e intercambio ${ }^{47}$. También justifica la institucionalización de sistemas estatales de $\mathrm{I}+\mathrm{D}+\mathrm{i}$ como canales de desarrollo de los Estados ${ }^{48}$.

\section{Las profesiones jurídicas en la economía del aprendizaje}

La economía del aprendizaje parece haber reducido el conocimiento a innovaciones tecnológicas, según se producen en determinadas industrias y servicios como la tecnología, las finanzas, las telecomunicaciones, la educación, la salud y los llamados servicios a empresas intensivos de conocimiento, que son los más potentes del ámbito económico. Cuando ese modelo dominante de industria e innovación tecnológica se traslada, sin más reflexión ni atención a sus especificidades, al ámbito de las profesiones del Derecho, lo que ocurre es que quedan reducidas a una de esas industrias, principalmente, las de servicios a empresas intensivos de conocimiento, en este caso, de conocimiento jurídico o más específicamente de ingeniería de conocimiento jurídico y de gestión de riesgos jurídicos. También la educación, incluida la jurídica, se convierte en una de estas industrias que proveen conocimiento

47 Riesco, M., El negocio es el conocimiento, op. cit., pp. 6 y 7.

48 Lundvall, B.-А., National systems of innovation: Toward a theory of innovation and interactive learning, 2, Londres, Anthem Press, 2010; Lundvall, B.-A., Johnson B., Andersen, E. S., Dalum, B., "National systems of production, innovation and competence building", Research policy, 31, No 2, 2002, pp. 213-231. 
y/o profesionales competentes y con creatividad de la que se espera también su propia cuota de innovación.

De manera concreta, las profesiones jurídicas, muchas de las cuales eran representativas de las llamadas profesiones liberales (abogacía, procura, registros, notarías, consultorías, etc.), están pasando a ser trabajo por cuenta ajena en grandes despachos o empresas de abogados(as), o bien trabajo autónomo, por medio del cual se contrata o subcontrata un determinado servicio jurídico. En cuanto a las profesiones jurídicas funcionarizadas (judicatura, fiscalía, abogacía del Estado, etc.) y concebidas como servicio público cuya razón de ser estaba en la garantía del interés general, la legalidad y los derechos constitucionales, experimentan ya el impacto del retroceso del Estado y su jurisdicción en beneficio de formas privadas de resolución de conflictos, como el arbitraje o la mediación, así como el empobrecimiento y desmantelamiento de las administraciones públicas de los Estados que se exige como solución a la crisis económica.

Por otra parte, el modelo de jurista que conoce todo el derecho y se ocupa de todo el caso (desde la recepción de la clientela hasta la litigación completa en el foro) está cediendo a la micro-especialización de las tareas jurídicas, no ya por ramas (penal, civil, laboral, etc.), sino dentro de un mismo litigio, dividido en diferentes tareas que acometen juristas con competencias o creatividad específicas para desarrollarlas: revisión documental, investigación de legislación, estrategia, tácticas, negociación, defensa, etc. ${ }^{49}$

En esta división de los trabajos jurídicos, las tareas más rutinarias que exigen manejar grandes cantidades de información se dejan a las TIC, mientras que para los seres humanos quedarían las actividades que requieren creatividad o intuición y que son el tipo de actividad que no pueden desempeñar las TIC, al carecer (aún) ${ }^{50}$ de esa capacidad de

49 Suskind, R., Tomorrow's Lawyers: An Introduction to Your Future, op. cit.

${ }^{50}$ Debe recordarse que la IA está integrada por diversas áreas que tratan de desentrañar cómo adquieren conocimiento los seres humanos a fin de imitarlos. Sobre estas cuestiones, véase Pino Díez, R., Gómez Gómez, A., De Abajo Martínez, N., Introducción a la inteligencia artificial: Sistemas expertos, redes neuronales artificiales y computación evolutiva, Oviedo, Universidad de Oviedo-Servicio de Publicaciones, 2001. 
La enseñanza del derecho en la economía del aprendizaje

aprendizaje o transformación de la información en conocimiento que tienen los humanos. Se trata de una percepción que se extiende también a las profesiones jurídicas, como se deduce del último informe de la empresa Deloitte, significativamente titulado Desarrollando el talento jurídico. Entrando en la empresa jurídica del futuro ${ }^{51}$.

Las profesiones jurídicas, como el resto de profesiones, han sido re-configuradas según los nuevos presupuestos de esta fase del capitalismo global, por lo que reflejarán los cambios laborales que ya se están produciendo en otras profesiones, como por ejemplo la exigencia de formación de por vida y la importancia de las competencias y la creatividad, cuya posesión y alcance dan la medida de la empleabilidad de una persona. A este respecto y según la propia OIT, la empleabilidad: "se refiere a las competencias y cualificaciones transferibles que refuerzan la capacidad de las personas para aprovechar las oportunidades de educación y de formación que se les presenten con miras a encontrar y conservar un trabajo decente, progresar en la empresa o al cambiar de empleo y adaptarse a la evolución de la tecnología y de las condiciones del mercado de trabajo" 52 .

En este escenario de incesante aprendizaje (como transformación innovadora del conocimiento ante los continuos problemas del entorno), se potencia la capacidad emprendedora y la responsabilidad personal, considerando que los individuos deben adaptarse a los cambios y ser críticamente autorreflexivos, innovadores, creativos, autodirigidos y automotivados, no sólo en la etapa escolar sino a lo largo de sus vidas, ya que las demandas cambian y los individuos deben aprender y olvidar competencias para darles respuesta ${ }^{53}$. Esto conduce a que

${ }^{51}$ Developing legal talent. Stepping into the future law firm. Disponible en https://www2. deloitte.com/uk/en/pages/audit/articles/developing-legal-talent.html (última visita 06/07/2017).

${ }^{52}$ R195 - Recomendación sobre el desarrollo de los recursos humanos, 2004 (núm. 195). Recomendación sobre el desarrollo de los recursos humanos: educación, formación y aprendizaje permanente. Ginebra, Suiza, 92a reunión CIT (17 junio 2004). Disponible en http:// www.ilo.org/dyn/normlex/es/f?p=NORMLEXPUB:12100:0::NO::P12100_ILO_ CODE:R195 (última visita 28/05/2017). La cursiva es mía.

53 OCDE, The definition and selection of key competencies executive summary, 27/5/2005, op. cit., pág. 17. 
se demande una formación para el empleo que potencie la formación en competencias, lo cual contradice las afirmaciones que hemos visto acerca de la imposibilidad de que las competencias (o al menos, las que consisten en aptitudes) se adquieran mediante la formación.

La posición de la OCDE al respecto ya se recogió en su programa Definition and Selection of Competencies: Theoretical and Conceptual Foundations (DeSeCo), iniciado en 1997. De manera principal, la OCDE sostiene que "el desarrollo sostenible y la cohesión social dependen de manera crítica de las competencias de todas nuestras poblaciones -entendiendo que la competencias incluyen conocimiento, habilidades, aptitudes y valores" 54 . Para la OCDE, si el éxito individual consiste en tener un empleo remunerado que aporte ingresos, salud, seguridad, participación política y redes sociales, y si el éxito para la sociedad consiste en la productividad económica, los procesos democráticos, la cohesión social, los derechos humanos, la igualdad y la sostenibilidad del medioambiente, su logro requiere de competencias individuales, competencias institucionales y la aplicación de las competencias individuales a los objetivos colectivos ${ }^{55}$.

La apuesta de la OCDE por esta relación específica entre competencias y empleo se evidencia en las herramientas (ítems y cuestionarios) que pone a disposición de los Estados miembros para evaluar las competencias cognitivas y relacionadas con el mundo del trabajo de adultos(as), a fin de que: "los individuos participen con éxito y la sociedad y la economía prosperen" 56 . Esa conexión continúa en sus últimos documentos dedicados al panorama de las competencias y al empleo, instando a los Estados a hacer lo que puedan para que sus trabajadores(as) hagan un uso completo de sus competencias en el trabajo, y a

${ }^{54}$ Ídem, pág. 4 y ss.

55 OCDE, The definition and selection of key competencies executive summary, 27/5/2005, op. cit., pág. 6.

56 Disponible en http://www.oecd.org/skills/evaluaciones-de-competencias/ (última visita 27/06/2017). 
La enseñanza del derecho en la economía del aprendizaje

no limitarse al desarrollo de políticas educativas en este asunto, sino a desarrollar también la innovación en el lugar del trabajo ${ }^{57}$.

Por su parte, el BM ofrece herramientas para evaluar las competencias de las personas trabajadoras y su empleabilidad a través de su programa STEP, o Skills towards Employability and Productivity (2014), haciendo también evaluaciones sobre el uso de las competencias en países en desarrollo. En cuanto a la UE (Unión Europea), su posición acerca de la formación en competencias quedó asentada en la Recomendación del Parlamento Europeo y del Consejo de 18 de diciembre de 2006, sobre las competencias clave para el aprendizaje permanente (2006/962/ $\mathrm{CE})$. Actualmente, su página web tiene un espacio dedicado a ofrecer: "opciones inspiradoras sobre competencias y empleos en Europa"58.

Estas profundas transformaciones que redefinen las profesiones jurídicas son vistas en ocasiones como una intensificación de su significación artesanal, de su carácter de oficios de juristas ${ }^{59}$. Sin embargo, lo que la economía del aprendizaje no garantiza es que los seres humanos, artesanos y creativos, sigan ostentando el poder de disposición sobre sus competencias o su creatividad, convertidas en una mercancía más; y al ser un tipo de conocimiento pegado a quien lo activa, tampoco está claro cómo se puede evitar la mercantilización del individuo que lo porta.

57 OCDE, Skills Outlook 2015. Youth. Skills and Employability, disponible en http:// dx.doi.org/10.1787/9789264234178. OCDE, Employment Outlook 2016, disponible en http://www.oecd-ilibrary.org/employment/oecd-employment-outlook-2016_emp1_ outlook-2016-en. OCDE, Skills Outlook 2017. Skills and Global Value Chains, disponible en http://www.oecd.org/publications/oecd-skills-outlook-2017-9789264273351-en. htm (última visita web indicadas 30/06/2017).

${ }^{58}$ Disponible en http://skillspanorama.cedefop.europa.eu/en/skill (última visita 27/06/2017).

59 Véase, por ejemplo, Díez-Picazo, L. (coord.), El oficio de jurista, Madrid, Siglo XXI, 2006. 


\title{
IV. La enseñanza del Derecho: hacia la formación de profesionales competentes
}

\begin{abstract}
Algunos de los cambios más evidentes que ha traído la economía del aprendizaje a la enseñanza del Derecho han sido: 1) alterar la relación profesorado/alumnado, enseñanza/aprendizaje, convirtiendo al segundo término del par en el protagonista de la formación jurídica. La transmisión acrítica de conocimiento (de tipo explícito o información) entre maestro-discípulo, tan habitual en la formación jurídica y sus típicas clases magistrales, y consecuencia de que el saber jurídico construido en la Universidad sea un saber dogmático y elitista basado en la autoridad incontestable de los maestros, es cuestionada en nombre de la formación de por vida y las exigencias de mantener su empleabilidad que se ciernen sobre quienes ejerzan las profesiones jurídicas. Son esta personas las que deben dirigir su proceso de formación para poder postularse siempre como profesionales competentes, y el profesorado, sea en la Universidad o en otros ámbitos formativos, sólo son guías $^{60}$. 2) Las universidades se integran en los sistemas nacionales de ciencia, los cuales tienen entre sus funciones la producción (investigación), transmisión (docencia) y transferencia de conocimiento ${ }^{61}$. Esta última irá dirigida a individuos y grupos como las empresas, que usarán al conocimiento para la producción de beneficios. Así lo señalan la $\mathrm{OCDE}^{62}$ y la UNESCO ${ }^{63}$. Pero la circunstancia de que las universidades hayan cobrado un interés estratégico en la competitividad de algunas empresas puede imponer determinados tipos y materias de investigación y enseñanza, como la biotecnología o las telecomunicaciones, marginado otros como las disciplinas humanísticas. 3) Muchas universidades se están dotando de la estructura y el funcionamiento de una empresa, mercantilizando sus servicios. En todo caso, los cen-

\footnotetext{
${ }^{60}$ Saavedra López, M. y Ruiz Resa, J.D., "Los estudios jurídicos en el Espacio Europeo de Educación Superior", en AA.VV., Entre la ética, la politica y el derecho. Estudios en homenaje al profesor Gregorio Peces-Barba, Madrid, Dykinson, 2008, pág. 1247-1280.

${ }^{61}$ OCDE, The Knowledge Based Economy, 1996, op. cit., pp. 21-24

${ }^{62}$ Ibidem.

${ }^{63}$ UNESCO, Informe mundial: Hacia las..., op. cit.
} 
La enseñanza del derecho en la economía del aprendizaje

tros educativos han pasado a ser, bajo la perspectiva de la OCDE, un negocio, y su alumnado, su clientela ${ }^{64}$, mientras que sus servicios son sometidos a controles de calidad como se hace en el resto de las empresas. 4) Puesto que la educación, incluida la jurídica, se erige en una de estas industrias que proveen conocimiento y/o profesionales competentes, se defiende que, como toda industria, debe liberalizarse y no estar monopolizada por las universidades. 5) Ese mismo carácter de industria del conocimiento que tienen los centros educativos como las universidades determina que contengan sus propios procesos de innovación. Las innovaciones docentes serían, pues, una dimensión más de la innovación de conocimiento que se lleva a cabo en las universidades, y que interactuaría con las innovaciones que se producen en las otras dos dimensiones: investigación y transmisión del conocimiento. $\mathrm{La}$ OCDE reconoce que aún se sabe muy poco acerca de cómo se produce la innovación en la enseñanza ${ }^{65}$.

En este contexto de mercantilización del conocimiento, lo que principalmente se espera de la formación universitaria es que provea, no individuos humanistas ni científicos críticos (Kant y Von Humboldt), ni tampoco meros técnicos que se limitan a aplicar, sin cuestionar, la ley del Estado (Napoleón) ${ }^{66}$, sino, como ya se ha visto, profesionales competentes y empleables que pongan en marcha, a su debido tiempo,

${ }^{64}$ Así se deduce del vocabulario de Hargreaves en sus informes para la OCDE, quien cree que las escuelas y Universidades deberían enseñar: "a sus clientes más efectiva y eficientemente" y sostiene que "[1] os pedagogos tendrán así que aprender a crear nuevo conocimiento sobre su negocio y a aplicarlo exitosamente en nuevas y muy inciertas condiciones". En Hargreaves, D., "La producción, intermediación y el uso del conocimiento en diferentes sectores", en OCDE, La administración del conocimiento en la sociedad del aprendizaje, op. cit., pág. 35. Las cursivas son mías.

${ }^{65}$ Sobre este particular véase OCDE, La administración del conocimiento en la sociedad del aprendizaje, op. cit.

${ }^{66}$ Sobre estos modelos de juristas, véase Salguero Salguero, M., "La tarea crítica de la filosofía jurídica en el espacio académico de la Facultad de Derecho", en Ruiz Resa, J.D. (ed.), Política, economía y método en la investigación y aprendizaje del derecho, Madrid, Dykinson, 2014, pág. 169-181; Saavedra López, M. y Ruiz Resa, J.D., "Los estudios jurídicos en el Espacio Europeo de Educación Superior", en AA.VV., Entre la ética, la politica y el derecho. Estudios en homenaje al profesor Gregorio Peces-Barba, Madrid, Dykinson, 2008, pp. 1247-1280. 
sus distintas competencias, creatividades o talentos, según las demandas de su entorno laboral. Como su inteligencia se aloja y limita en su cuerpo, los seres humanos constituyen una mente encarnada que debe superar sus limitaciones extendiéndose en objetos o prótesis externas como las TIC.

Por consiguiente en la enseñanza del Derecho, como en otras enseñanzas universitarias, se ha afianzado (a pesar de las contradicciones que eso implica) la formación y evaluación por competencias ${ }^{67}$. Teniendo en cuenta que son categorías desarrolladas en el ámbito laboral y empresarial, no extraña que se traigan las dinámicas propias de esos ámbitos al de la enseñanza, también del Derecho, lo que por otra parte parece un paso natural al haberse configurado la educación como una empresa más.

En este nuevo contexto de formación para la acción y la gestión/ producción de conocimiento, resultan especialmente adecuadas las metodologías de instrucción basadas en el learning by doing, como el aprendizaje basado en problemas o en proyectos, para garantizar al menos un escenario donde se accionen las competencias. Aunque la apuesta expresa por el learning by doing se detecta en la obra del psicólogo y filósofo John Dewey ${ }^{68}$, lo cierto es que ha tenido un fuerte impulso gracias a metodologías articuladas en el ámbito económico y empresarial. Así, para Rosenberg, existen diversos tipos de aprendizaje que se llevan a cabo en el ámbito económico: 1) en la fase de $\mathrm{I}+\mathrm{D}, 2$ ) en la de producción y 3) en la de uso de la tecnología: en los procesos de I+D el aprendizaje ocurre en la generación de nuevas tecnologías, ${ }^{69}$ en la etapa de fabricación mediante el learning by doing, y en la etapa de utilización del producto por el usuario final, mediante el learning by

${ }^{67}$ Gil Flores, J., "La evaluación de competencias laborales", Educación XXI, 10, 2007, pp. 83-106. (Disponible en http://revistas.uned.es/index.php/educacionXX1/article/ view/298/254. Última visita 22/05/2018)

${ }^{68}$ Ruiz, G., "La teoría de la experiencia de John Dewey: significación histórica y vigencia en el debate teórico contemporáneo", Foro de Educación, 11, No. 15, 2013, pp. 105-106.

${ }^{69}$ Rosenberg, N., Inside the black box technology and Economics, Cambridge, Cambridge University Press, 1982. 
La enseñanza del derecho en la economía del aprendizaje

using. En cada uno de estos tres procesos de aprendizaje se producen innovaciones tecnológicas que ocurren después de diseñarse el producto. Por otra parte, Schön sigue directamente la estela de Dewey en su libro La formación de profesionales reflexivos: Hacia un nuevo diseño de la enseñanza y el aprendizaje de las profesiones ${ }^{70}$; mientras que la utilización de problemas para innovar y crear nuevo conocimiento se considera esencial en las empresas, y ha llevado al desarrollo de metodologías para hallar soluciones como el design thinking, brainstroming, seis sombreros para pensar, mapas mentales, scamper, TRIZ (acrónimo ruso de "teoría de la solución creativa de problemas") o QFD (Quality Function Deployment: Despliegue de la Función de Calidad $)^{71}$.

En todo caso, y teniendo en cuenta estos presupuestos, ni el método del caso es learning by doing, como advertía Jerome Frank, pues estudia casos ya resueltos ${ }^{72}$; ni lo es ningún otro método que, como éste, consista en la transmisión, captación y aplicación de contenido explícito (esto es, información) ya existente. Aunque el método del caso se vea como una innovación docente en los sistemas de Derecho civil, cuya enseñanza se basa en la lección magistral que transmite principios y conceptos jurídicos, en los sistemas del Common Law su existencia responde a las vicisitudes propias de su derecho: un origen predominantemente procesal y la diversidad de sus tribunales y procedimientos (principalmente en Gran Bretaña), imposibilitaba una formación en principios y conceptos generales, como sí permitían en cambio los sistemas de Derecho civil (también entendidos como sistemas de derecho continental codificados $)^{73}$. En este sentido, el hecho de que

${ }^{70}$ Dewey, J., La formación de profesionales reflexivos: Hacia un nuevo diseño de la enseñanza y el aprendizaje de las profesiones, Barcelona, Paidós, 1992.

${ }^{71}$ Sobre estas cuestiones, véase Castillo-Vergara, M., Alvarez-Marin, A., Cabana-Villca, R., "Design thinking: cómo guiar a estudiantes, emprendedores y empresarios en su aplicación", Ingeniería Industrial, XXXV, No. 3, septiembre-diciembre, 2014, pp. 301-311.

72 Frank, J., "Why Not a Clinical Lawyer School", University of Pennsylvania Law Review, 81, 1933, pág. 907-923. Disponible en http://digitalcommons.law.yale.edu/cgi/viewcontent.cgi?article $=5092 \&$ context $=$ fss_papers. (Ultima visita 22/05/2018)

${ }^{73}$ Véase Lageot, C., "L'enseignement du droit en France et an Grande-Bretagne : regard comparé», en Raimbault, Ph., La pedagogique au service du droit, Toulouse, LGDJ-Presses de l'Univesité Toulouse 1 Capitole, 2011, pág. 41 y ss. 
hasta muy recientemente universidades como la de Oxford no hayan incorporado entre sus estudios los de Derecho (lo que significa que se podían ejercer las profesiones jurídicas sin título universitario oficial al efecto), o que la formación jurídica para el ejercicio profesional estuviera y siga estando controlada por los colegios de abogados, muestra también que en los sistemas del Common Law la enseñanza y las profesiones jurídicas han discurrido menos controladas por las políticas de los Estados-nación y más conectadas a las actividades e intereses de la actividad privada. Esta percepción de la enseñanza y las profesiones jurídicas es la que parece haberse tenido en cuenta para trazar el camino de las transformaciones a nivel global de las profesiones jurídicas y la enseñanza del Derecho en la economía del aprendizaje, lo que no extraña si se tiene en cuenta que muchas de las empresas que han servido de modelo para caracterizar esta economía, así como muchos de sus más conspicuos teóricos y defensores, se ubican en el contexto de la cultura jurídica del Common Law.

En todo caso y para calibrar lo que se puede esperar de la formación de juristas en competencias, hay que tener en cuenta que hay muchos países miembros de la OCDE que vienen de una dictadura política. Tal es el caso de España, proceso que se prolonga hasta 1978 y al que sustituye un sistema político democrático que no abrogó todas las instituciones y los valores sociales, políticos y jurídicos. Siguiendo el ejemplo español, hay que tener en cuenta qué tipo de juristas y facultades de Derecho necesitó la dictadura franquista: una élite afín a sus principios, con unas facultades de Derecho de donde fueron apartadas, encarceladas o eliminadas las personas no afines. En tal contexto se potenció la promoción profesional, no de los más competentes sino de los más fieles, y la transmisión de un saber jurídico dogmático imposible de cuestionar para evitar el ostracismo laboral o por pura supervivencia ${ }^{74}$. Semejante cultura académica y político-jurídica que se

${ }^{74}$ Entiendo el ostracismo laboral como el ostracismo en el lugar de trabajo, en el sentido de ser apartado/a de los mejores puestos en las universidades (catedráticos/as, directores/as de departamentos, etc.), algo que les solía ocurrir a quienes cuestionaran el derecho vigente, es decir, el derecho de la dictadura. 
transmitió a través de un plan de estudios aprobado en 1953 y vigente hasta el año 2000 en la mayoría de las Universidades, ha calado en numerosas generaciones de juristas e incluso entre quienes ya se formaron durante la democracia. Y aún más, sigue presente entre referentes doctrinales y en las metodologías de investigación que aún dominan nuestras facultades, así como en muchos usos forenses y en la estructura, gobierno y funcionamiento del poder judicial y de otros sectores de las profesiones jurídicas.

\section{Conclusiones}

La enseñanza del Derecho sigue actualmente la estela que marca una política económica global, la cual mercantiliza el conocimiento erigiéndolo en fuente de riqueza y desarrollo. En un contexto así, las profesiones jurídicas y su formación se redefinen, liberalizándose, computarizándose y especializándose. Se les exige a quienes se dedican a ellas una formación de por vida (la cual no sólo se recibe en las Universidades), para así actualizar y/o adquirir nuevas competencias; es decir, ese tipo de conocimiento pegajoso con el que se renueva e innova el conocimiento explícito o información, lo que garantiza su empleabilidad. Sin embargo, esta percepción escamotea la discusión por un lado, sobre la comunidad política y jurídica en la que se ejercen las profesiones jurídicas y se enseña el Derecho. Por el otro, las consecuencias que tienen para amplias capas de la población cada vez más empobrecidas, estos cambios en las profesiones jurídicas, el creciente debilitamiento de la garantía de acceso a las instituciones de justicia y el auge del contrato como fuente jurídica fundamental.

El escenario resulta desasosegante, y en él quienes desempeñan o enseñan las profesiones jurídicas carecen ya de la formación humanística que se reclamaba en otras épocas, como en la Ilustración, para reflexionar sobre el derecho, su legitimidad o sus fines. La formación tecnificadora y antihumanista que se inició con el positivismo legalista y que buscó ofrecer juristas imparciales que aplicaran las leyes del Estado, parece dar un giro con la formación de juristas con creativi- 
dad, cuya intuición y saber tácito que accionan con las nuevas tareas surgidas de la especialización en las funciones tradicionales, aún les diferencia (y por esa razón, aún les sigue haciendo imprescindibles) de las TIC.

El objetivo principal de este giro no parece ser la mejora de la comunidad política, ni contempla el compromiso cada vez más debilitado con la realización de los derechos humanos o los principios de la democracia. Tal situación no puede modificarse sólo desde la enseñanza del Derecho.

En fin, el saber jurídico tiene su propio recorrido hacia la innovación, tanto a través de la investigación directa sobre el Derecho (realizada por juristas o especialistas de otras disciplinas), como a través de los procesos de interpretación y aplicación del Derecho que incorporan metodologías innovadoras (ocurran en un juicio, en una negociación de despacho o en la resolución de un caso en una facultad de Derecho), que podría llevarse a cabo mediante una metodología docente que es a su vez innovadora. Pero este es un aspecto poco conocido o poco asumido por los(las) miembros de las profesiones jurídicas, e incluso por las organizaciones internacionales que han impulsado la economía del aprendizaje; y aún más, este mecanismo lo observamos también en las autoridades políticas y académicas que han realizado las últimas reformas de los planes de estudios jurídicos. La ausencia, por el momento, de más indagaciones sobre estos asuntos puede impedir no sólo cuestionar, sino incluso cumplir sumisamente con las exigencias de la economía del aprendizaje. 
La enseñanza del derecho en la economía del aprendizaje

\section{Bibliografía}

Agut Nieto, S. y Gau Gumbau, R. M., "Una aproximación psicosocial al estudio de las competencias", Proyecto social: Revista de relaciones laborales, 9, 2001, pp. 13-24. (Disponible en https://dialnet.unirioja. es/servlet/articulo?codigo=209924. Última visita 22/05/2018).

Arthur, W. B., Increasing returns and path dependence in the economy, Michigan, The Michigan University Press, 1994.

Banco Mundial Institute Development Studies, Building knowledge economies: Advanced strategies for development, Washington, The International Bank for Reconstruction and Development / The World Bank, 2007, pp. 23 y 24. Disponible en http://siteresources.worldbank.org/KFDLP/Resources/4611971199907090464/BuildingKEbook.pdf (Ultima visita 22/05/2018).

Benavides, O. A., "La innovación tecnológica desde una perspectiva evolutiva", Cuadernos de Economía, XXIII, N 41, Bogotá, 2004, pp. 49-70.

Camacho, J. A. y Rodríguez, M., "España ante la economía del conocimiento: el papel de los servicios a empresas intensivos de conocimiento", Revista Asturiana de Economía, 31, 2004, pp. 177-202.

Capra, F., La trama de la vida. Una nueva perspectiva de los sistemas vivos, Barcelona, Anagrama, 1998.

Castillo-Vergara, M., Alvarez-Marin, A., Cabana-Villca, R., "Design thinking: cómo guiar a estudiantes, emprendedores y empresarios en su aplicación", Ingeniería Industrial, XXXV, No. 3, septiembre-diciembre, 2014, pp. 301-311.

Dewey, J., La formación de profesionales reflexivos: Hacia un nuevo diseño de la enseñanza y el aprendizaje de las profesiones, Barcelona, Paidós, 1992.

Díez-Picazo, L. (coord.), El oficio de jurista, Madrid, Siglo XXI, 2006.

Estanny, A., "El impacto de las ciencias cognitivas en la filosofía de la ciencia", Eidós. Revista de Filosofia de la Universidad del Norte, 6, mayo 2007, pp. 26-61. (Disponible en http://www.redalyc.org/ pdf/854/85400603.pdf. Última visita 22/05/2018).

Faure, E., Herrera, F., Kaddoura, A.-R., López, H., Petrovski, A., V. Rahnema, M., Champion Ward, F., Aprender a ser. La educación del 
futuro, Alianza-UNESCO, 1973, pág. 28 y ss. Versión española Carmen Paredes de Castro. (Disponible en http://unesdoc.unesco.org/ images/0013/001329/132984s.pdf. Última visita 30/06/2017).

Frank, J., "Why Not a Clinical Lawyer School", University of Pennsylvania Law Review, 81, 1933, pp. 907-923. (Disponible en http:// digitalcommons.law.yale.edu/cgi/viewcontent.cgi?article $=5092 \&$ context=fss_papers. Última visita 22/05/2018).

García García, E., "Teoría de la mente y ciencias cognitivas", en L. Feito Grande (ed.), Nuevas perspectivas cientificas y filosóficas sobre el ser humano, Madrid, Universidad Pontificia de Comillas, 2007, pp. 17-54.

Gil Flores, J., "La evaluación de competencias laborales", Educación XXI, 10, 2007, pp. 83-106.

González Romero, A., "Conocimiento, innovación y crecimiento económico", $M i+d$. Revista electrónica, 2006 (Edición especial: 20 años de la ley de la ciencia. 1986-2006). (Disponible en http://www. madrimasd.org/revista/revistaespecial1/articulos/gonzalez.asp. Última visita 01/06/2017).

Hargreaves, D., "La producción, intermediación y el uso del conocimiento en diferentes sectores", en OCDE, La administración del conocimiento en la sociedad del aprendizaje, París/Bogotá, Mayol ediciones/OCDE, [2000] 2006, pp. 35-70.

Krüguer, K., "E1 concepto de 'sociedad del conocimiento'", Revista bibliográfica de geografia y ciencias sociales, Universidad de Barcelona, XI, $\mathrm{N}^{\mathrm{o}}$ 683, 25 de octubre de 2006. (Disponible en http://www. ub.edu/geocrit/b3w-683.htm. última visita 30/06/2017).

Lageot, C., "L'enseignement du droit en France et an Grande-Bretagne : regard comparé», en Raimbault, $\mathrm{Ph}$., La pedagogique au service du droit, Toulouse, LGDJ-Presses de l'Univesité Toulouse 1 Capitole, 2011, pp. 41-56.

Le Boterf, G., De la compétence. Essai sur un attracteur étrange, Paris, Les Éditions d'organisation, 1994.

Lundvall, B.-Å, y Johnson, B., "The learning economy", Journal of Industry Studies, 1, No 2, Diciembre, 1994, pp. 21-42. 
La enseñanza del derecho en la economía del aprendizaje

Lundvall, B.- $\AA$, "The economics of knowledge and learning", en Christensen, J y Lundvall, B.-A (eds.), Product Innovation, Interactive Learning and Economic Performance (Research on Technological Innovation, Management and Policy), 8, Emerald Group Publishing Limited, 2004, pp. 21-42.

Lundvall, B.-A., "Entender la función de la educación en la economía del aprendizaje: la contribución de la economía", en OCDE, $L a$ administración del conocimiento en la sociedad del aprendizaje, Bogotá, OCDE, Mayol ediciones, 2006, pp. 3-34.

Lundvall, B.-Å., National systems of innovation: Toward a theory of innovation and interactive learning, 2, Londres, Anthem Press, 2010.

Lundvall, B.-Å., Johnson B., Andersen, E. S., Dalum, B., "National systems of production, innovation and competence building", Research policy, 31, N² 2, 2002, pp. 213-231.

Martínez León, I. y Ruiz Mercader, J., "Los procesos de creación del conocimiento: el aprendizaje y la espiral de conversión del conocimiento", en XVI Congreso Nacional y XII Congreso hispano-francés de AEDEM: la empresa intangible, Asociación Europea de Dirección y Economía de la Empresa (AEDEM), Alicante, Universidad de Alicante, 2002; (Disponible en http://repositorio.upct. es/handle/10317/613. Última visita 22/05/2018).

Nelson, R., Physical and Social Technologies, and Their Evolution, Pisa, Italia, LEM Working Paper, Series $N^{\circ}$ 9, June, Laboratory of Economics and Management, Sant'Anna School of Advance d Studies, 2003.

Nonaka, I, Byosière, $\mathrm{Ph}$., "La creación de conocimiento regional: un proceso de desarrollo social", en CLUSTER CONOCIMIENTO, Las sociedades del conocimiento, Bilbao, 2000.

Nonaka, I. y Takeuchi, H., The knowledge-creating company: How Japanese Companies Create the Dynamics of Innovation, New York-Oxford, Oxford University Press, 1995.

Nye, M. J., Michael Polanyi and his generation: Origins of the Social Construction of Science, Chicago, University Chicago Press, 2011.

OCDE, The definition and selection of key competencies executive summary, 27/5/2005. Disponible en http://www.oecd.org/edu/skills-be- 
yond-school/definitionandselectionofcompetenciesdeseco.htm (última visita 30/06/2017).

OCDE, Skills Outlook 2015. Youth. Skills and Employability. Disponible en http://dx.doi.org/10.1787/9789264234178 (última visita 30/06/2017).

OCDE, Employment Outlook 2016. (Disponible en http://www.oecd-ilibrary.org/employment/oecd-employment-outlook-2016_empl_outlook-2016-en. última visita 30/06/2017).

OCDE, Skills Outlook 2017. Skills and Global Value Chains. (Disponible en http://www.oecd.org/publications/oecd-skills-outlook-20179789264273351-en.htm. última visita 30/06/2017).

OCDE, La administración del conocimiento en la sociedad del aprendizaje, París/Bogotá, Mayol ediciones/OCDE, [2000] 2006.

OCDE, The Knowledge Based Economy, París, 1996. (Disponible en https://www.oecd.org/sti/sci-tech/1913021.pdf. última visita 01/04/2016).

Perales Palacios, F.J., "Desarrollo cognitivo y modelo constructivista en la enseñanza-aprendizaje de las ciencias", Revista Interuniversitaria de Formación del Profesorado, 13, Enero-Abril, 1992, pp. 173189. (Disponible en https://dialnet.unirioja.es/servlet/articulo?codigo $=618847$. Última visita 22/05/2018).

Pino Díez, R., Gómez Gómez, A., De Abajo Martínez, N., Introducción a la inteligencia artificial: Sistemas expertos, redes neuronales artificiales y computación evolutiva, Oviedo, Universidad de Oviedo-Servicio de Publicaciones, 2001.

Polanyi, M., Personal Knowledge. Towards a Post-Critical Philosophy, Chicago, University Chicago Press, 1962.

Pozo, J. J., Teorías cognitivas del aprendizaje, Madrid, Morata, 1997.

Riesco González, M., El negocio es el conocimiento, Madrid, ediciones Díaz de Santos, 2006.

Riesco González, M., "El enfoque por competencias en el EEES y sus implicaciones para la enseñanza y el aprendizaje", Tendencias Pedagógicas, 13, 2008, pp. 79-105. 
Romo Santos, M., "Treinta y cinco años de pensamiento divergente. Teoría de la creatividad de Guilford", Estudios de Psicología, núm. 27-28, 1987, pp. 175-192.

Rosenberg, N., Inside the black box technology and Economics, Cambridge, Cambridge University Press, 1982.

Ruiz, G., "La teoría de la experiencia de John Dewey: significación histórica y vigencia en el debate teórico contemporáneo", Foro de Educación, 11, № 15, 2013, pp. 103-124.

Saavedra López, M. y Ruiz Resa, J.D., "Los estudios jurídicos en el Espacio Europeo de Educación Superior", en AA.VV., Entre la ética, la politica y el derecho. Estudios en homenaje al profesor Gregorio PecesBarba, Madrid, Dykinson, 2008, pp. 1247-1280.

Salguero Salguero, M., "La tarea crítica de la filosofía jurídica en el espacio académico de la Facultad de Derecho", en Ruiz Resa, J.D. (ed.), Politica, economía y método en la investigación y aprendizaje del derecho, Madrid, Dykinson, 2014, pp. 169-181.

Schunk, D. H., Teorías del aprendizaje, trad. J.F. Javier Dávila Martínez, México, Pearson, 1997.

Senge, P. M., The Fifth Discipline. The art and practice of the learning organization, Nueva York, Doubleday, 1990.

Suskind, R., Tomorrow's Lawyers: An Introduction to Your Future, Oxford, Oxford University Press, 2013.

UNESCO, Informe mundial: hacia las sociedades del conocimiento, París, 2005.

UNESCO, La educación encierra un tesoro, Madrid, Santillana/UNESCO, 1997.

Vilaseca, J., Torrent, J., y Díaz, Á., La economía del conocimiento. Paradigma tecnológico y cambio estructural, Working Paper Serie, UOC (Universitat Oberta de Catalunya), 2002. (Disponible en http://www. uoc.edu/in3/dt/20007/20007.pdf. Última visita 22/05/2018).

Von Hippel, E., "Sticky Information and the Locus of Problem Solving: Implications for Innovation", Management Science, 40, $\mathrm{N}^{\circ} 4$, 1994, pp. 429-439. 